\title{
Robotic Psychology \\ What Do We Know about Human-Robot Interaction and What Do We Still Need to Learn?
}

\author{
Ruth Maria Stock \\ Founder of Leap in time: www.leap-in-time.de \\ Technical University Darmstadt, Germany \\ RSH@bwl.tu-darmstadt.de
}

\author{
Mai Anh Nguyen \\ Technical University Darmstadt, Germany \\ maianh.nguyen@bwl.tu-darmstadt.de
}

\begin{abstract}
"Robotization", the integration of robots in human life will change human life drastically. In many situations, such as in the service sector, robots will become an integrative part of our lives. Thus, it is vital to learn from extant research on human-robot interaction (HRI). This article introduces robotic psychology that aims to bridge the gap between humans and robots by providing insights into particularities of HRI. It presents a conceptualization of robotic psychology and provides an overview of research on service-focused human-robot interaction. Theoretical concepts, relevant to understand HRI with are reviewed. Major achievements, shortcomings, and propositions for future research will be discussed.
\end{abstract}

\section{Introduction}

Robots - Curse or Blessing for Humans?

The introduction of "Industry 4.0" has brought development in our everyday life [25]. How does this change affect our lives and what does it mean to us?

According to the forecast of the International Federation of Robotics from 2017, more than 1.7 million new industrial robots will be installed in factories all over the world. Moreover, by 2020 a significant growth of about 1.2 million service robots, which will be used in the fields such as logistics, public relations or medicine, is to be expected [18]. In view of this forecast, it becomes apparent that real-life and virtual reality melt together gradually, resulting in a completely new circumstance, both on a private and professional level.

On closer examination of different expert opinions on robotic, these developments are evaluated mixed. While proponents emphasize the great potential of robots to maximize human benefits, e.g., by supporting humans in their daily lives or simply by entertaining humans [18], opponents of robots claim that the robots soon may steal human jobs [12].

The introduction of robots can no longer be prevented. Not only in manufacturing areas, but also in numerous service industries, robots are increasingly used to support working people, e.g., by providing training, or customers, e.g., by advising customers in the supermarket. Thus, it is important to understand how humans react psychologically to these robots. This article aims to provide an overview of current research on relevant psychological concepts and empirical findings regarding human responses to service robots.

According to ISO 8373, a robot is defined as "an automatically controlled, reprogrammable, multipurpose manipulator with three or more axes" that can function autonomously [33]. Currently available robots can be categorized into two groups based on their usage domain: assisting robots or interactive stimulation robots, which are also referred to as personal robots [27].

Interactive stimulation robots are human-oriented and focus on communication. They satisfy rather psychological needs by executing social, entertaining, educational, recreational, rehabilitative, and therapeutic activities on a personal level [27].

This article focuses on interactive and stimulant robots in the field of service. In general, they can be defined as "systems that function as smart, programmable tools that can sense, think, and act to benefit or enable humans or extend/ enhance human productivity" [17, p. 3]. Such robots "are designed to support and service humans through physical and social interactions" [19, p. 1503]. We decided on a more human focused research framework by only analyzing humanoid or android service robots. Humanoid robots refer to robots with an anthropomorphized physical appearance, which compromises some form of a body with arms, legs, and a head. An android is "an artificial system designed with the ultimate goal of being indistinguishable from humans in its external appearance and behavior" [29, 
p. 298]. Androids even should be capable "of sustaining natural relationships with people" [36, p. 8]. Hence, humanoid or android service robots are often used in the field of public relations (e.g., as a receptionist or a waiter).

As the definitions of robots show, robots have the purpose to serve humans in a benevolent and beneficial way. Nevertheless, different studies show that the benefits of robots still are not fully exhausted [11].

Robotic psychology represents a research field that can offer some explanation for this phenomenon. It is an emerging research field that studies the psychological significance of robots' behavior and its intertwining with elements of physical and social environments. Specifically, it attempts to systematically analyze the compatibility between humans and robots on a sensorimotor, emotional, cognitive, and social level [28]. In doing so, principles of differential psychology are applied to determine the individuality of human-robot interactions (HRI) and to define robots' 'personality' and its psychological effect on humans [27]. In this context, a compatibility between both parties occurs when human expectations concerning the robot match with the robots' attributes and expressions. Thus, this research field goes beyond the traditional fields of human factors or humanmachine interaction. In fact, it is based on psychological principles [27] that enable to reveal psychological mechanisms determining the course of HRIs [13]. Hence, it is necessary to make a shift from a 'mechano-centric' view on HRI that mainly focuses on engineering aspects, to a 'human-oriented' one, laying the focus on human values within the technological framework [27]. Robotic psychology puts human values and needs in the focus of technological processes of robots. Thus, robotic psychology aims to bridge the gap between technical-oriented sciences and social sciences.

This article provides in-depth insights into the emerging research field of robotic psychology. In doing so, a conceptualization of robotic psychology is provided to explore essential psychological principles necessary for understanding and optimizing HRI. Along the lines of this model, extant service-oriented robotic research will be reviewed. Finally, propositions for future research will be deduced.

\section{Robotic Psychology}

HRI is goal-driven, which means that it is determined by a mutual goal that both parties strive to create through interaction. Hence, HRIs are defined by the successfulness, showing in the degree of goal attainment [28]. Robotic psychology strives for a successful and compatible collaboration between humans and robots by making humans the subject of research and applying human values toward robots. Therefore, it is essential to define human responses to artificial robotic behaviors and investigate underlying mechanisms [21]. These insights enable a deeper understanding of the interaction and collaboration between humans and robots. The conceptual framework of robotic psychology is depicted in Figure 1.

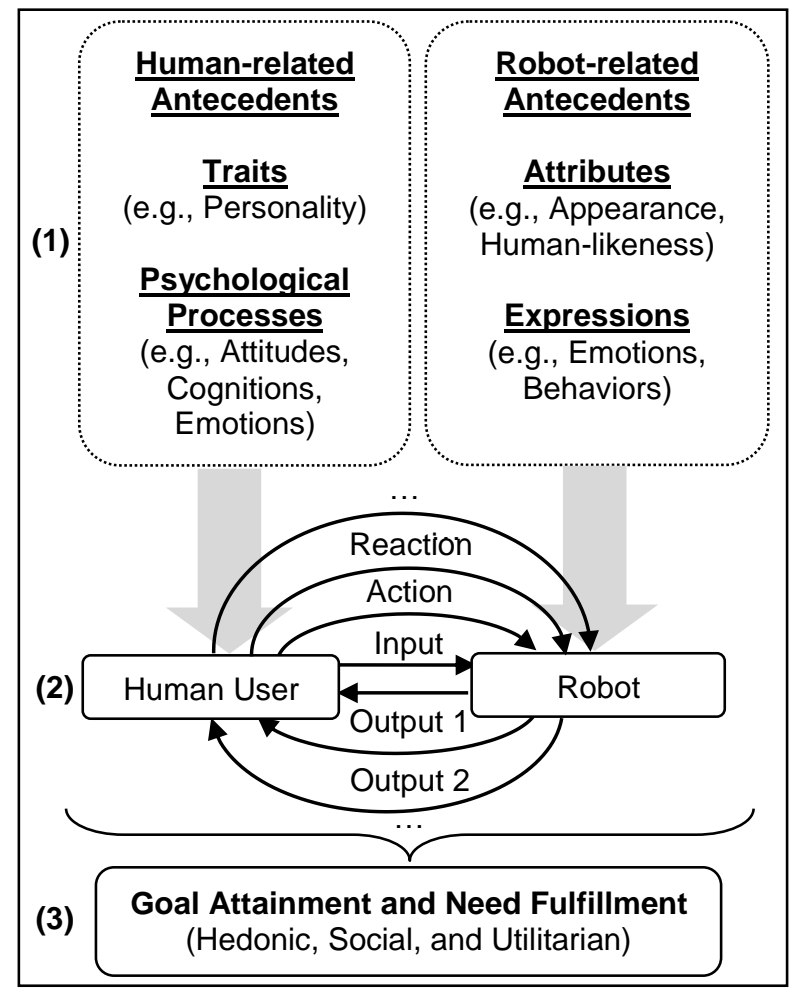

Figure 1. Conceptualization of robotic psychology

The core of the model refers to HRI, including important antecedents of HRI, such as human traits, psychological processes, robotic attributes and expressions. This model goes beyond the behavioral research of HRI since it strives to uncover paradigmatically the relation between cause and effect that determines humans in their experience and behavior. Furthermore, it enables the description, explanation, and prediction of human experience and behavior in the context of a robotic environment. Thereby, robotic psychology incorporates three sequential levels, namely the (1) individual level, (2) interaction level, and (3) outcome level.

Individual level. This level examines each interacting party separately and encompasses, traits, processes, attributes, and expressions that determine the behavioral pattern. From the human's perspective, 
personality traits and intra-psychological processes such as attitudes are examined. On the robot's side, artificial characteristics (e.g., emotions or behaviors) attributes (e.g., human-likeness) are studied.

Interaction level. On this level the dynamic effects of human and robotic antecedents are examined. Here, we adapt the input-output-view on HRI that is defined by a specific sequence of actions. Accordingly, we consider HRI as a mutual influencing process that follows the defined sequence. Hence, it is possible to detect the direction of influences. In the following example, we will regard a service-related HRI between a robotic waiter and a customer since we focus on service robots. First, the customer provides either an active input to the robot, e.g., by ordering a specific drink, or a passive input, e.g., by walking by the robot and unintentionally activating it. The robot processes this input und responds through an output that can either consist of verbal signals, e.g., by answering to the order, or non-verbal signals, e.g., by nodding. Thereupon, the customer refers to that output and carries out an action that can be (1) cognitive, e.g., by thinking about the respond, (2) emotional, e.g., by looking forward to the drink, or (3) behavioral, e.g., by asking a question. Subsequently, the robot processes and answers this question, referring to the second output. Then, the customer reacts to this answer that consequently evokes another output from the robot. Hence, HRI are constantly driven by sequential actions depending on each other. This sequence of actions proceeds until the mutual goal of both parties is attained.

Outcome level. On this level, the degree of goal attainment is examined. Since a goal is always driven by an underlying need, we address both goal attainment and need fulfillment as important outcomes of a successful HRI. Thereby, we distinguish between hedonic, social, and utilitarian needs. Hedonic needs, such as learning, refer to intrinsic, emotive needs that activate experiences such as fun, sensation, and joy. In the context of HRI, the need for entertainment represents a hedonic need. Utilitarian needs, as increasing the productivity through HRI, demonstrate rather rational and functional ones [3, 40]. Social needs, such as connection with the robot, describe the desire for belonging, association, and acceptance by others [30]. These outcomes allow us to define the degree of success of HRI.

This conceptualization reveals new behavioral patterns of humans that need to be distinguished from experiences during human-computer interactions and human-human interactions. The reason for this is the nature of robots that derives from both technical devices and humans. While robots clearly are technical creatures, they somehow show human features, as in the appearance or actions. To gain insight into this new behavioral pattern, we raise two questions:

(1) How do humans appraise robots?

(2) How do robots affect humans?

\section{Literature Review}

In this section, we address the raised questions by reviewing the state of the art in extant literature. Since we are focusing on service robots, the questions will be answered along this focus. Table 1 compromises an overview of different studies from the last 15 years dealing with the relationship of humans and stimulant or social service robots. In doing so, we conducted a two-step analysis. First, we only included empirical studies that deal with the human-robot appraisal happening before a HRI. Second, we selected studies that incorporate a real life HRI and focuse on robothuman influencing.

The studies in Table 1 revealed valuable insights into human users' appraisal and experience of HRI. For instance, personality, expectations, and attitudes turned out to be great influencing factors for robot appraisal. Besides, the robot's expressiveness, presence, and mood influenced people's behavior and emotional state. In the following, we use these findings as a basis for the analysis of the two stated questions. Based on this, we will discuss essential psychological conceptualizations vital for understanding robotic psychology.

\subsection{How do humans appraise robots?}

Understanding, how humans appraise robots, enables us to locate weaknesses in the design of robots and to improve it. After a brief introduction of the appraisal process, we will elaborate on how the appraisal of robots is distorted by the identified antecedents (e.g., personality, attitudes, or emotions).

Cognitive appraisal is a psychological categorization process of a situation to determine the impact of this situation on the self [18]. Hereby, it is essential to determine whether the situation affects or even disturbs the individual well-being or a specific meaningful goal. A relevant appraisal triggers emotions that influence the subsequent behavior [23].

3.1.1. Personality. Personality comprises personality traits that pervasively influence the way information are processed and used, subsequently leading to the consistency in behavior [22]. Hence, personality traits affect unconsciously or subconsciously, how robots are appraised and how humans, feel and behave toward them. 
Table 1. Literature review on service robots.

\begin{tabular}{|c|c|c|c|c|}
\hline \multirow{4}{*}{ 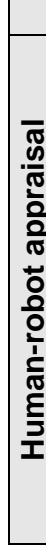 } & Authors & Setting & Measures & Main findings \\
\hline & $\begin{array}{l}\text { Andrist, S. Mutlu, B., } \\
\text { \& Tapus, A. (2015) }\end{array}$ & $\begin{array}{l}\text { Assistive robot } \\
\mathrm{N}=40 \text { adults }\end{array}$ & $\begin{array}{l}\text { Big Five, global motivation } \\
\text { toward activities in life, total } \\
\text { number of puzzles solved, } \\
\text { perceived robot performance }\end{array}$ & $\begin{array}{l}\text { Positive effect of personality matching } \\
\text { between human and robot as well as } \\
\text { technical background on duration of HRI. }\end{array}$ \\
\hline & $\begin{array}{l}\text { Lee, H., Sung, J., } \\
\text { Šabanović, S., \& } \\
\text { Han, J. (2012) }\end{array}$ & $\begin{array}{l}\text { Domestic robot } \\
N=48 \text { American } \\
N=20 \text { South } \\
\text { Korean }\end{array}$ & $\begin{array}{l}\text { Visual representation of ideal } \\
\text { domestic robot, motivation for } \\
\text { robot design, design factors }\end{array}$ & $\begin{array}{l}\text { User expectations and preferences } \\
\text { concerning look and feel, interaction } \\
\text { mode, social roles, and desired tasks of } \\
\text { the robot differ due to culture. }\end{array}$ \\
\hline & $\begin{array}{l}\text { Reich, N. \& Eyssel, } \\
\text { F. (2013) }\end{array}$ & $\begin{array}{l}\text { Service robot } \\
N=366 \text { German }\end{array}$ & $\begin{array}{l}\text { Need for cognition, desire for } \\
\text { control, chronic loneliness, } \\
\text { positive attitudes toward } \\
\text { robots, robot anxiety, interest } \\
\text { in science and technology, } \\
\text { prior robot experience }\end{array}$ & $\begin{array}{l}\text { Interest in science and technology and } \\
\text { prior robot experience determines the } \\
\text { attitudes toward robots. } \\
\text { Need for cognition and chronic loneliness } \\
\text { correlate with a positive robots perception. }\end{array}$ \\
\hline & $\begin{array}{l}\text { Heerink, M., Kröse, } \\
\text { B., \& Evers, V. } \\
(2010)\end{array}$ & $\begin{array}{l}\text { Robot in } \\
\text { eldercare } \\
\mathrm{N}=40 \text { elderly } \\
\text { adults }\end{array}$ & $\begin{array}{l}\text { Conversational } \\
\text { expressiveness, acceptance, } \\
\text { intention to use, social } \\
\text { presence }\end{array}$ & $\begin{array}{l}\text { Positive correlation between robot's social } \\
\text { capability with social presence and } \\
\text { conversational expressiveness. } \\
\text { Positive correlation between } \\
\text { conversational expressiveness and } \\
\text { intention to use robot. }\end{array}$ \\
\hline & $\begin{array}{l}\text { Kanda, T., Shiomi, } \\
\text { M., Miyashita, Z., } \\
\text { Ishiguro, H., \& } \\
\text { Hagita, N. (2010) }\end{array}$ & $\begin{array}{l}\text { Communication } \\
\text { robot in shopping } \\
\text { mall } \\
\mathrm{N}=235\end{array}$ & $\begin{array}{l}\text { Impression of robot, } \\
\text { usefulness of and interest in } \\
\text { the provided information, } \\
\text { perceived familiarization }\end{array}$ & $\begin{array}{l}\text { Positive effect of frequency of HRI on } \\
\text { robot evaluation. } \\
\text { HRI affects participants' shopping } \\
\text { behavior as an advertisement effect and } \\
\text { interest effect. }\end{array}$ \\
\hline 옹 & $\begin{array}{l}\text { Kirby, R., Forlizzi, J., } \\
\text { \& Simmons, R. } \\
(2010)\end{array}$ & $\begin{array}{l}\text { Robotic } \\
\text { receptionist } \\
\mathrm{N}=123\end{array}$ & $\begin{array}{l}\text { Robot valence, robot arousal, } \\
\text { naturalness, likeability, } \\
\text { entertainment, person } \\
\text { valence }\end{array}$ & $\begin{array}{l}\text { People can identify the robot's } \\
\text { expressions (e.g., happiness, sadness) } \\
\text { and can distinguish between the intensity } \\
\text { levels of robotic artificial emotions. } \\
\text { Correlation between the human } \\
\text { interaction pattern and the robot's mood. }\end{array}$ \\
\hline 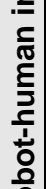 & $\begin{array}{l}\text { Kuno, Y., Sadazuka, } \\
\text { K., Kawashima, M., } \\
\text { Yamazaki, K., } \\
\text { Yamazaki, A., \& } \\
\text { Kuzuoka, H. (2007) } \\
\end{array}$ & $\begin{array}{l}\text { Museum guide } \\
\text { robot } \\
\mathrm{N}=12\end{array}$ & $\begin{array}{l}\text { Total number of participants' } \\
\text { movement }\end{array}$ & $\begin{array}{l}\text { People show a behavioral orientation } \\
\text { toward the robots' head movement in } \\
\text { terms of nodding and mutual gazing. }\end{array}$ \\
\hline 总 & $\begin{array}{l}\text { Rodriguez-Lizundia, } \\
\text { E., Marcos, S., } \\
\text { Zalama, E., \& } \\
\text { Gordaliza, A. (2015) } \\
\end{array}$ & $\begin{array}{l}\text { Bellboy robot } \\
\mathrm{N}=95\end{array}$ & $\begin{array}{l}\text { Distance within } \mathrm{HRI}, \\
\text { interaction initiator, } \\
\text { interaction duration, } \\
\text { interaction type }\end{array}$ & $\begin{array}{l}\text { The level of a robot's presence affects } \\
\text { social interaction with the robot in terms of } \\
\text { proxemics, duration of interaction, and the } \\
\text { type of interaction. }\end{array}$ \\
\hline & $\begin{array}{l}\text { Wada, K., Shibata, } \\
\text { T., Saito, T., \& Tanie, } \\
\text { K. (2004) }\end{array}$ & $\begin{array}{l}\text { Robot in } \\
\text { eldercare } \\
\mathrm{N}=23 \text { elderly } \\
\text { adults }\end{array}$ & $\begin{array}{l}\text { Face scale, POMS, biological } \\
\text { stress (urinary test), } \\
\text { evaluation through nursing } \\
\text { stuff }\end{array}$ & $\begin{array}{l}\text { Robot-assisted activity can improve mood } \\
\text { and the ability to recover from stress that } \\
\text { decreases mental impoverishment of the } \\
\text { nursing. }\end{array}$ \\
\hline & $\begin{array}{l}\text { Yamazaki, A., } \\
\text { Yamazaki, K., } \\
\text { Burdelski, M., Kuno, } \\
\text { Y., \& Fukushima, M. } \\
(2010)\end{array}$ & $\begin{array}{l}\text { Museum guide } \\
\text { robot } \\
\mathrm{N}=46 \text { Japanese }\end{array}$ & $\begin{array}{l}\text { Non-verbal response as gaze } \\
\text { and head nodding, timing of } \\
\text { responses }\end{array}$ & $\begin{array}{l}\text { Participants respond with head turn, gaze, } \\
\text { and head nod corresponding to robots' } \\
\text { head movements at interactionally } \\
\text { significant places during its talk and at } \\
\text { transition-relevance places during the } \\
\text { interaction. }\end{array}$ \\
\hline
\end{tabular}

Walters et al. examined the influence of subjects' personality traits on personal spatial zones in a HRI and found out that subjects' personality profiles influence personal spatial zones in HRI [42]. For example, they observed that persons who score high on the personality trait proactiveness, keep more distance when interacting with a robot. This distance discloses information about the relationship between the interacting partners from the human point of view. Further studies revealed the importance of matching the personality of both interaction partners for robot acceptance, indicating that examining the human personality is an essential preliminary investigation to further a successful HRI [20, 41]. These studies 
demonstrate that the effect of human personality on HRI is expressed on diverse levels such as the verbal, non-verbal, or emotive-behavioral level.

Finally, these findings demonstrate the influencing role of personality in HRI that highlights the relevance of matching human and robotic artificial personality.

3.1.2. Attitudes toward robots. Attitudes refer to a mental and neural state of readiness which is shaped through experience. They influence the individual's reaction to the environment by assigning either positive or negative values to it. This in turn determines whether the individual acts toward or against the environment [2].

This dialectic view is also discussed in the context of robotic psychology. Thereby, negative toned attitudes of humans about robots are of great interest. In this context, Nomura et al. developed the Negative Attitudes Toward Robots Scale (NARS) to identify beliefs and opinions humans generally have about robots [34]. The scale is classified into three subscales that focus on the negative attitude toward (1) interaction with robots, (2) social influence of robots, and (3) emotional interaction with robots. In the course of an experimental HRI, they ascertained that the negative attitude toward robots is related to concrete behaviors humans express toward robots, such as avoidance concerning emotion expression, talk, touch, and communication. Hence, a negative attitude toward robots is associated with negative toned behaviors [34]. Further studies revealed cultural background, prior experience with robots, or other technical devices as important influencing factors for the establishment of negative attitudes toward robots (see also Table 1).

3.1.3. Emotions toward robots. As mentioned emotions emerge in the context of appraisals. A commonly examined emotion that arises in the context of HRI is anxiety that human feel when imagining or engaging in a HRI. Nomura, Kanda, Suzuki, and Kato developed the Robot Anxiety Scale (RAS) that measures both anticipated and real state-like anxiety in the context of HRI [34]. This scale consists of three subscales concerning the anxiety toward (1) communication capacity of robots, (2) behavioral characteristics of robots, and (3) discourse with robots. Corresponding to the theoretical assumption, several studies have shown that robotic anxiety correlates with various behavioral reactions such as avoidance or distancing, and mental reactions (e.g., acceptance) [5]. Hence, emotions as a part of appraisal represent an essential linkage between cognition and behavior that enables to anticipate human behavior in HRI.

To sum up, the appraisal of humans regarding robots are based on personality manifestations and existent attitudes. Hence, human appraisal of robots are distorted toward existent manifestations to some extent. This implies that humans typically appraise robots in respect of their present opinions and beliefs about robots. Furthermore, emotions demonstrate an important mechanism that regulate the course of HRI. In the context of service robots, humans engage in the HRI with specific experiences they gained through prior services they received from humans or other technical devices. These experiences shape the expectations, attitudes, behaviors, and emotions humans have when engaging in a HRI.

\subsection{How do robots affect humans?}

The literature review revealed three main channels through which robots affect humans: the emotional, cognitive, and emotive-cognitive channel (see Table 1). In the following, we elaborate psychological mechanisms underlying the robot-human influencing. Specifically, we will take a close look at the emotional contagion, cognitive biases, and uncanny valley paradigm.

3.2.1. Emotional contagion. Emotional contagion refers to "the tendency to automatically mimic and synchronize expressions, vocalizations, postures, and movements with those of another person's and, consequently, to converge emotionally" [15, pp. 153154]. Furthermore, it can be considered as a form of social influencing since it is defined as "a process in which a person or group influences the emotions or behavior of another person or group through the conscious or unconscious induction of emotion states and behavioral attitudes" [38, p. 50]. A successful emotional contagion takes place in several steps. This article transfers the process of emotional contagion in the context of HRI to point out, how robots affect humans through their artificial emotions (see Figure 2).

During HRIs robots express emotions through verbal and non-verbal signals, which are perceived by humans (emotional encounter). Humans process these signals in two different ways, namely through primitive emotional contagion and emotional comparison processes (emotional transfer).

The primitive emotional contagion is a very fast and subconscious process by which an individual automatically mimics and synchronizes the robotic facial expression, speech pattern, and movements. These mimicry experiences provide an afferent feedback and trigger the subjective emotional experience. 


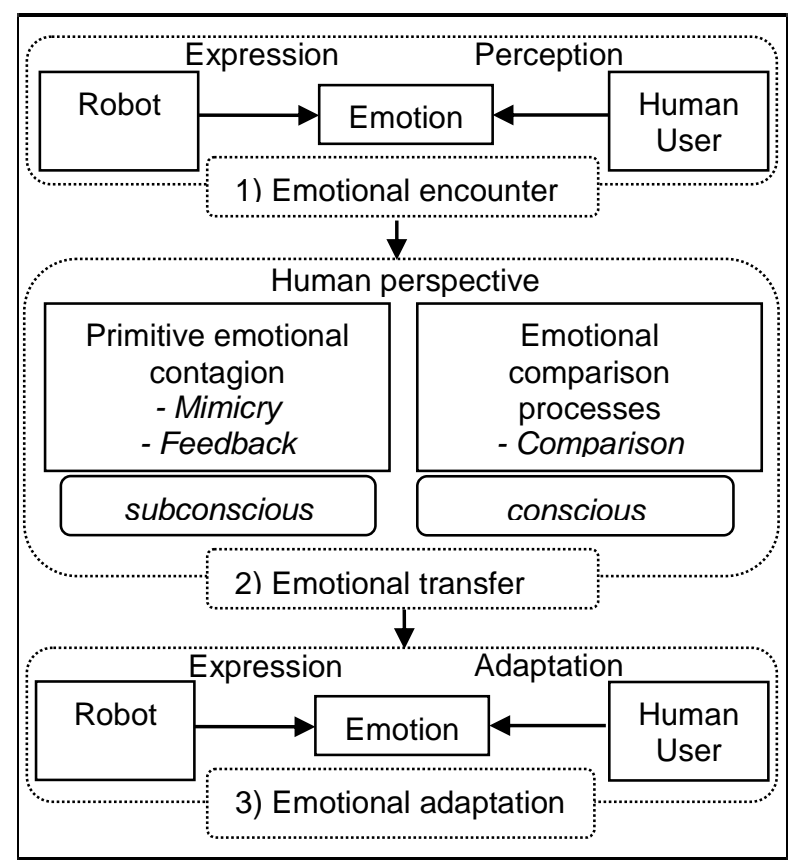

Figure 2. Emotional contagion in HRI

Contrary to this, emotional comparison processes are conscious and cognitive. Specifically, an individual intentionally compares his or her feelings to those observed by the robot. The individual then adapts himor herself to the environment with the goal to respond adequately (emotional adaptation) [15, 4]. Hence, this process can be seen as a type of social comparison in that the robot represents the benchmark.

In extant research, only few studies focus on emotional contagion from robots to humans [39, 43]. For instance, Xu et al. set up an experimental study, in which participants engaged in a simple imitation game with the humanoid robot NAO by imitating its movements [43]. It became apparent, that the robot's mood, demonstrated through parameterized behaviors, transferred to the participants' mood. Furthermore, Leite et al. conducted an experiment with a social robot in the setting of a chess game and determined that social robots, showing empathy as a form of emotional contagion in a HRI, scored higher on the friendship function [26]. This study shows the urge to study emotional contagion in the field of robotic psychology since emotional contagion can be considered as a mechanism contributing to a successful relationship between humans and robots.

Especially, for service robots this mechanism is of great interest since it represents a possibility to gain emotional access to humans. The insights in emotional contagion in the context of service-related HRI reveal that robots are able to stimulate customers emotionally and thus to some extent are able to regulate the HRI. Besides, since the emotional comparison process is a mechanism of adaptation to the environment, it would be interesting to transfer this process to robots to test, to what extent this contributes to the acceptance and integration of robots in the human circle. Stock proposed a model of artificial emotional contagion during service encounters, in which emotional contagion is examined during HRIs and human-human interactions [39].

3.2.2. Cognitive biases. Cognitive biases focus exclusively on the cognitive perspective. Specifically, humans are supposed to establish a virtual mind, which is distorted by cognitive biases. Here, we focus on the following cognitive biases: post-truth bias, automation bias, and anthropomorphism bias.

Post-truth bias. As we already elaborated in the context of emotional contagion, robots are likely to affect humans emotionally. Especially, when people feel a "cognitive ease", they are in a good mood, like what they see, believe what they hear, trust their intuitions, and feel that the current situation they are experiencing is comfortably familiar [20]. Since robots are capable of emotionalizing people through mechanisms such as emotional contagion, we assume that they are able to influence human cognitions. The impact of such a cognitive manipulation shows in the post-truth bias that prevails in the field of politics and was first coined by Steve Tesich in 1992. The Oxford Dictionaries define this term as "circumstances in which objective facts are less influential in shaping public opinion than appeals to emotion and personal belief". This implies that highly emotionalized humans are rather guided by their emotions than by facts. In the context of HRI this could mean that robot are able to guide the interaction by emotionalizing them.

Automation bias. This bias occurs within the framework of decision-making and refers to "omission and commission errors resulting from the use of automated cues as a heuristic replacement for vigilant information seeking and processing" [32, p. 47]. Omission errors occur when required actions are not taken by the human because they are not informed by the aid system. On the contrary, commission errors arise when humans uncritically follow the information or directives of the aid system whereas they are inconsistent with other sources of information. In fields such as domestic or nursing social service robots are also used as a decision-making support system [35]. Thus, the described errors can occur while receiving the robotic services. This can be explained by the human tendency to attribute great power and authority to automated aid devices as robots [32]. Thus, humans tend to trust blindly robotic decision making.

Anthropomorphism bias. Anthropomorphism is defined as "the tendency to imbue the real or imagined 
behavior of nonhuman agents with humanlike characteristics, motivations, intentions, or emotions" [10, p. 864]. Hence, the human perception of robots is distorted by their erroneous assignment of human attributes to robots. Epley et al. state that the degree of anthropomorphism of non-human entities such as robots depends on three psychological determinants: (1) accessibility and applicability of anthropocentric knowledge, (2) motivation to explain and understand the behavior of other agents, and (3) desire for social contact and affiliation. It is assumed that humans are more likely to anthropomorphize when these factors are on high levels [10].

Besides, the degree of anthropomorphism correlates with the perception and evaluation of robots [9]. Interestingly, the direction of correlation depends on the degree of similarity between humans and the other agent [11]. In the study of Eyssel and Kuchenbrandt, German participants should help developers to optimize a new robot prototype by evaluating the robot concerning attributes such as warmth, psychological closeness, and design [11]. Thereby, they provided information about the ethnicity of the robot which was either Turkish or German. The participants evaluated the German robot superior on the interesting attributes, although they differed in no further aspects. In fact, the relationship between the degree of anthropomorphism and positive evaluation outcomes is not linear, which will be discussed in the following section.

In this section we highlighted the role of service robots as emotional and cognitive influencer of humans' virtual mind. The described cognitive biases demonstrate unconscious mechanisms that can have tremendous consequences in the handling with robots. Hence, particularly in the human-related service fields, such as education, consulting or care, the user's awareness of these biases is vital. However, cognitive biases do not only offer disadvantages but advantages too since the biases can be used to ameliorate the design according to the role of the service robot. For instance, the positive effect of the anthropomorphism bias can be used to increase the acceptance of an educational robot, which could have positive effects on the learning outcome of students. In conclusion, it is necessary to find a balance between the human and virtual mind for cognitive biases to be used effectively.

3.2.3. Uncanny valley paradigm. The uncanny valley paradigm was first introduced by Masahiro Mori in 1970 and describes the human perception of robots, expressed through the perceived familiarity, in dependence to the human likeness of different entities [31]. It predicts that the "difficulty distinguishing between a humanlike object and its natural human counterpart will evoke negatively valenced feelings and cognitions" [8, p. 1], known as the "uncanny valley". We define human likeness as the extent to which robots more closely resemble people that also includes the physical humanlike similarity to robots $[29,8]$. Figure 3 depicts the human perception of different entities in dependence to the degree of human likeness. The either static or moving entities range from industrial robots, via zombies through to humans.

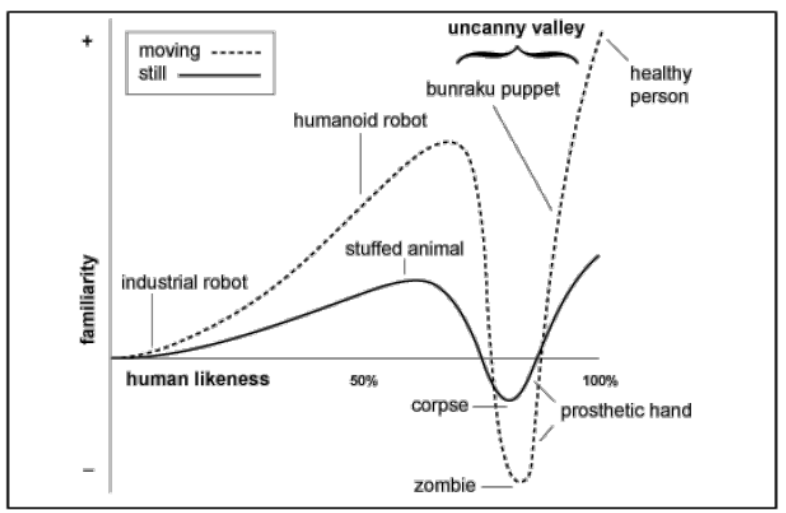

Figure 3. The uncanny valley [31, p. 33]

To begin with, the lowest level includes industrial robots, which function in nearly all manufacturing areas [18]. The construction of industrial robots is mainly focused on features (e.g., speed, precision, and enormous power) to conduct standardized production processes. Hence, they do not look like humans and humans feel minimal affinity toward them, so that the familiarity is assumed to be rather low [31].

The next level of human likeness refers to humanoid robots its designs are human-oriented, so they take human-looking forms [31]. Humans tend to associate them with children or people with disabilities, such that they feel some sympathy and familiarity toward them. Still, some human perception of robots also may be dominated by fear and reluctance when that human likeness passes a certain level [31].

This zone represents the uncanny valley, which "refers to a state of perceptual or cognitive experience at which an increasingly humanlike figure becomes strange, rather than more familiar or acceptable" [36, p. 8]. In addition, it is described as a negative state that is "characterized by feelings of unease and the uncanny" $[8$, p. 1] and negatively valenced cognitions. Often, this uncanny valley is occupied by android robots.

Researchers offer various explanations for why humans feel reluctant to interact with or are afraid of android robots [e.g., 14]. From a specialized processing perspective, humans perceive robots as threats, like diseases [29] or sources of emotional irritation [7]. Research on the affective response perspective instead 
suggests that androids create a sense of fear [29] and difficulties in distinguishing humans from robots [36].

Finally, the highest level of human-likeness is associated with real humans. Accordingly, humans feel the greatest likability for real humans, because they create minimal dissonance and uncertainty and are more familiar than any robot. Up to date, research on the uncanny valley paradigm still produces mixed results [14]. All in all, the human perception of robots seems to be a highly complex process of which underlying mechanisms are not fully explored.

This paradigm is vital especially for the robotic service field since it shows the dependency of robotic appearance, perception, and acceptance. Thus, the robotic appearance and the task the service robot occupies should be matched.

To conclude, humans are influenced on various channels that clearly interfere with each other. It seems as if humans perceive robots under the influence of a "cognitive filter" that is triggered by the robot. Since extant research still shows a deficit concerning the explanation of robot-human influencing, it is necessary to conduct further research in this field.

\section{Discussion}

It became apparent that the relationship between both parties is complex and needs to be studied holistically on different levels, such as the individual, interactive and outcome level (see Figure 1). To close this holistic view we will discuss the outcome level in the following. We stated that the relationship between humans and robots is always driven by a mutual goal. To reach this goal, both humans and robots need to go through a process of dynamic interaction and merge to an effective team. This requires humans to accept robots as a part of the human social circle. Some researchers claim that the design of robots should not be completely oriented toward the nature of humans, resulting in a synthetic human, but rather toward human characteristics that facilitate the social interaction [9].

Accordingly, the artificial sociability represents an indispensable attribute that robots should hold. A robot's sociability implicates "the ability to interact with people in an entertaining, engaging, or seamless manner" [6, p. 181]. Therefore robots need to be emotional intelligent [9]. Goleman highlights selfawareness, managing emotions, motivation, empathy, and social skills as five basic emotional competencies. These capabilities enable robots to "monitor one's own and others' emotions, to discriminate among them, and to use the information to guide one's thinking and actions" [37, p. 189]. Especially, in the context of service robots, it would be useful to integrate the sociability in the design robots. Thereby, the degree of sociability should be oriented toward the individual needs to maintain the adaptability of robots. Hence, the dynamism between humans and robots emerges at the right origin, namely the human needs, and leads into the right goal, namely the social embodiment [9].

This article seeks to review the state of the art of social service robots in the context of robotic psychology and to identify fundamental psychological mechanisms determining the relationship between humans and robots. In the beginning, we proposed a model of robotic psychology in which psychological antecedents and processes are integrated. Based on this, a literature review on HRI with social service robots was conducted to identify how humans appraise robots and how robots affect humans. In doing so, we revealed vital psychological mechanisms concerning the human-robot appraisal and robot-human influencing (e.g., uncanny valley paradigm, emotional contagion and cognitive biases).

These findings contribute to extant research by giving a broad overview on social service research. Furthermore, contrary to previous research, we laid the focus on the explanation of processes within HRI and discussed underlying psychological mechanisms with focus on emotional and cognitive aspects. Hence, we clearly aimed at the goal of robotic psychology, namely to uncover paradigmatically the relation between cause and effect that determines humans in their experience and behavior with robots. This enables the description, explanation, and prediction of human experience as well as behavior in the context of a robotic environment.

\subsection{Research Implications}

This article provided insights into particularities and theoretical concepts of HRI and an overview of research on service-oriented HRI. Thereby, we revealed major achievements as well as shortcomings that need to be addressed. On the basis of the literature review, we could point out some methodological shortcomings.

First, the majority of studies on service-related HRI have been conducted in a laboratory setting and are restricted in terms of the intensity of the interaction. Specifically, they require users to observe or respond to gestures or bodily expressions by the robot. Furthermore, few studies refer to a natural service context, in which the researchers do not offer any type of intervention. This is detrimental since it does not offer the possibility to provide the naturalness of the HRI and does not enable researchers to investigate the robot's role as a service provider. 
Second, extant HRI literature mainly focuses on the analysis on the behavioral level. This might be important to observe the dynamic between human and robots. Nevertheless, it does not provide a deep understanding on why humans think and act toward robots the way they do.

\subsection{Research Propositions}

In the following several research propositions corresponding to the mentioned shortcomings are discussed.

Proposition 1: Future research should draw greater attention to real life conditions of HRI.

Future research should take more strongly real life settings into account when designing their research. For instance, HRI could be examined with robots in a hotel setting at the information desk or in an education setting such as at a training center of a company. These studies should follow a particular system for designing HRI experiments that offer deeper insights in the human-robot relationship [16].

Proposition 2: Challenges of HRI that should be examined in future research.

One major challenge we detected within robotic psychology is the human Black Box during HRI. Future research should focus on throwing light on this by examining intra-psychological processes that determine the behavior toward robots such as stress. We address this shortfall by proposing a model of customer coping with a robotic service failure that shall be compared with customer responses to a human service failure. We have developed an empirical design for an experiment to test this model by using the humanoid robot Pepper in a hotel check-in situation. This model incorporates quantifiable measures through technical devices and gives insight in emotivecognitive processes.

The realization of these propositions can contribute to a deeper understanding of HRI and will enable us to establish a culture of valued and accepted service robots into our human society.

\section{Acknowledgements}

The authors thank the Förderverein für Marktorientierte Unternehmensführung, Marketing und Personalmanagement e.V. for the great support.

\section{References}

[1] S. Adnrist, B. Mutlu, and Tapus, "Look Like Me: Matching Robot Personality via Gaze to Increase Motivation", CHI '15 Proceedings of the 22rd Annual ACM
Conference on Human Factors in Computing Systems, New York, April 18-23, 2015, pp. 3603-3612.

[2] Ajzen, I., and Fishbein, M. The Handbook of Attitudes, Lawrence Erlbaum Associates Mahwah, NJ, 2005.

[3] B. J. Babin, W. R. Darden, and M. Griffin, ,Work and/or Fun: Measuring Hedonic and Utilitarian Shopping Value", Journal of Consumer Research (20), 1994, pp. 644-656.

[4] S. G. Barsade, "The Ripple Effect: Emotional Contagion and Its Influence on Group Behavior", Administrative Science Quarterly (47), 2002, pp. 644-675.

[5] C. Bartneck, T. Suzuki, T. Kanda, and T. Nomura, „The Influence of People's Culture and Prior Experiences with Aibo on Their Attitude towards Robots“, AI \& Society (21), 2006, pp. 217-230.

[6] C. Breazeal, "Social Interactions in HRI: The Robot View", IEEE Transactions on Systems, Man, and Cybernetics (34), 2004, pp. 181-186.

[7] T. Chaminade, J. Hodgins, and M. Kawato, "Anthropomorphism Influences Perception of ComputerAnimated Characters' Actions", Social Cognitive and Affective Neuroscience, 2007, pp. 206-216.

[8] M. Cheetham, I. Pavlovic, N. Jordan, P. Suter, and L. Jancke, "Category Processing and the Human Likeness Dimension of the Uncanny Valley Hypothesis: Eye Tracking Data", Frontiers in Psychology (4), 2013, pp. 1-12.

[9] B. R. Duffy, "Anthropomorphism and the Social Robot", Robotics and Autonomous Systems (42), 2003, pp. 177.190.

[10] N. Epley, A. Waytz, and J. T. Cacioppo, "On Seeing Human: A Three-Factor Theory of Anthropomorphism", Psychological Review (114), 2007, pp. 864-886.

[11] F. Eyssel, and D. Kuchenbrandt, „Social Categorization of Social Robots: Anthropomorphism as a Function of Robot Group Membership“, British Journal of Social Psychology (51), 2012, pp. 724-731.

[12] C. B. Frey, and M. A. Osborne, "The Future of Employment: How Susceptible are Jobs to Computerisation?", Oxford Martin School (OMS) working paper, Oxford, 2013, pp. 1-72.

[13] Goodrich, M. A., \& Schultz, A. C., Human-Computer Interaction, now Publishers, Hanover, 2007, pp. 203-275.

[14] K. Gray, and D. M. Wegner, "Feeling Robots and Human Zombies: Mind Perception and the Uncanny Valley", Cognition (125), 2012, pp. 125-130.

[15] Hatfield, E., Cacioppo, J. T., and Rapson, R. L., Emotional Contagion, Cambridge University Press, Cambridge, 1993. 
[16] N. Homburg, "How to Include Humanoid Robots into Experimental Research: A Multi-Step Approach", Proceedings of the 51th Hawaii International Conference on System Sciences, Hawaii, January 3-6, 2018, pp. 4423-4432.

[17] Hüttenrauch, H., From HCI to HRI: Designing Interaction for a Service Robot, KTH, Stockholm, 2006.

[18] International Federation of Robotics, World Robotics 2016, VDMA, Frankfurt am Main, 2017.

[19] S. Ivanov, C. Webster, and K. Berezina, "Adoption of Robots and Service Automation by Tourism and Hospitality Companies", Revista Turismo \& Desenvolvimento (27/28), 2017, pp. 1501-1517.

[20] Kahneman, D. and Egan, P., Thinking Fast and Slow, New York, Farrar, Straus and Giroux, 2011.

[21] R. Kirby, J. Forlizzi, and R. Simmons, “Affective Social Robots", Robotics and Autonomous Systems (58), 2010, pp. 322-332.

[22] Lazarus, R. S., Cognitive and Personality Factors Underlying threat and Coping. In M. H. Appley, and R. Trumbull (Eds.), Psychological Stress. Issues in Research, Appleton-Century Crofts, New York, 1967, pp. 151-181.

[23] Lazarus, R. S., Psychological Stress and the Coping Process, McGraw Hill, New York, 1966.

[24] Lazarus, R. S., and Folkman, S., Stress, Appraisal, and Coping, Springer Publishing Company, New York, 1984.

[25] J. Lee, H.-A. Kao, and S. Yang, "Service Innovation and Smart Analytics for Industry 4.0 and Big Data Environment", Procedia CIRP (16), 2014, pp. 3-8.

[26] I. Leite, A. Pereira, S. Mascarenhas, C. Martinho, R. Prada, and A. Paiva, "The Influence of Empathy in HumanRobot Relations", International Journal of Human-Computer Studies (71), 2012, pp. 250-260.

[27] A. V. Libin, and E. V. Libin, "Person-Robot Interactions from the Robopsychologists' Point of View: The Robotic Psychology and Robotherapy Approach", Proceedings of the IEEE (92), 2004, pp. 1789-1803.

[28] A. V. Libin, and E. V. Libin, "Robotic Psychology", Encyclopedia of Applied Psychology (3), 2004, pp. 295-298.

[29] K. F. MacDorman, and H. Ishiguro, "The Uncanny Advantage of Using Androids in Cognitive and Social Science Research", Interaction Studies (7), 2006, pp. 297 337.

[30] D. M. MacGregor, "The Human Side of Enterprise", Management Review (24), 1957, pp. 41-49.

[31] M. Mori, "The Uncanny Valley", Energy (7), 1970, pp. 33-35.
[32] K. L. Mosier, L. J. Skitka, S. Heers, and M. Burdick, "Automation Bias: Decision making and Performance in High-Tech Cockpits", The International Journal of Aviation Psychology, 2009, pp. 47-63.

[33] Murphy, R. R., Introduction to AI Robotics, MIT Press, Cambridge, 2000.

[34] T. Nomura, T. Kanda, T. Suzuki, and K. Kato, "Prediction of Human Behavior in Human-Robot Interaction Using Psychological Scales for Anxiety and Negative Attitudes Toward Robots", IEEE Transactions on Robotics (24), 2008, pp. 442-451.

[35] J. Pineau, M. Montemerlo, M. Pollack, N. Roy, and S. Thrun, "Towards Robotic Assistants in Nursing Homes: Challenges and Results", Robotics and Autonomous Systems (42), 2003, pp. 271-281.

[36] C. H. Ramey, "The Uncanny Valley of Similarities Concerning Abortion, Baldness, Heaps of Sand, and Humanlike Robots", IEEE-RAS International Conference on Humanoid Robots, Tsukuba, Japan, 2005, pp. 8-13.

[37] P. Salovey, and J. D. Mayer, "Emotional Intelligence", Imagination, Cognition, and Personality (9), 1990, pp. 185211.

[38] G. Schoenewolf, "Emotional Contagion: Behavioral Induction in Individuals and Groups", Modern Psychoanalysis (15), 1990, pp. 49-61.

[39] R. M. Stock, "Emotional Transfer from Frontline Social Robots to Human Customers during Service Encounters: Testing an Artificial Emotional Contagion Modell", International Conference on Information Systems, 2016, pp. $1-11$.

[40] R. M. Stock, P. Oliveira, and E. von Hippel, "Impacts of Hedonic and Utilitarian User Motives on the Innovativeness of User-Developed Solutions", Journal of Product Innovation Management (32), 2014, pp. 389-403.

[41] A. Tapus, C. Tapus, and M. Mataric, "User-Robot Personality Matching and Robot Behavior Adaptation for Post-Stroke Rehabilitation Therapy", Intelligent Service Robotics (1), 2008, pp. 169-183.

[42] M. L. Walters, K. Dautenhahn, R. te Boekhorst, K. L. Koay, C. Kaouri, S. Woods, C. Nehaniv, D. Lee, and I. Werry, „The Influence of Subjects' Personality Traits on Personal Spatial Zones in a Human-Robot Interaction Experiment", IEEE International Workshop on Robots and Human Interactive Communication, 2005, pp. 347-352.

[43] J. Xu, J. Broekens, K. Hindriks, and M. A. Neerincx, "Robot Mood is Contagious: Effects of Robot Body Language in the Imitation Game", International Foundation for Autonomous Agents and Multiagent Systems, 2014, pp. 973-980. 